\title{
Evaluating the Bioavailability of Calcium Phosphate Nanoparticles as Mineral Supplement in Broiler Chicken
}

\author{
M. P. Vijayakumar* and V. Balakrishnan \\ Department of Animal Nutrition, Madras Veterinary College, Chennai - 600 007, India; \\ vijinutrition@gmail.com,drbalakrishnanphd@yahoo.co.in
}

\begin{abstract}
An experiment was carried out with the objective of determining the bioavailability of calcium phosphate nanoparticles by supplementing calcium phosphate nanoparticles at graded levels from 50 to $100 \%$ of phosphorus content to the standard source (Dicalcium phosphate - coarse particle) at 10 per cent increment. Tibial bone morphometry, bone and serum mineral profile and carcass characters in broiler chicken were studied with mash form of feed in 70 male broiler chicks (Cobb 400) from day 1 to 28 indicated that the there was no significant variation in the parameters studied. The tibial bone ash, calcium and phosphorus content are unison for both the control and $50 \%$ calcium phosphate nanoparticles supplemented groups. The results indicated that the bioavailability of phosphorus in calcium phosphate nanoparticles was 200 per cent when compared to dicalcium phosphate. This finding may help the poultry managers to minimize the feed transport cost and also minimize the mineral wastages.
\end{abstract}

\section{Introduction}

Supplementing calcium in poultry rations does not create a great impact on feed cost as most of the calcium sources are relatively cheaper. However, the trend is different with regard to phosphorus supplementation as phosphorus supplements are costlier and hence its inclusion creates an impact on feed cost. In the recent past various strategies have been explored to reduce the feed cost of poultry by reducing the cost of mineral supplementation. One such strategy is development of area specific mineral mixture and its supplementation which eliminates the supplementation of unwarranted minerals. However, this strategy is not recommended to intensive poultry farming. The ways for exploring methodologies for enhancing bioavailability of minerals especially phosphorus is yet another strategy to reduce the poultry feed cost. Nanoparticle-sized ingredients might increase the functionality or bioavailability of ingredients and nutrients, and thereby minimise the concentrations needed in the food product ${ }^{1}$. Nano form of supplementation increases the surface area which possibly could increase absorption ${ }^{2}$ and thereby utilization of minerals leading to reduction in the quantity of supplements and through higher bioavailability.

Current research on mineral nutrition is focused on reducing the inclusion levels and increasing the absorption of minerals by reducing their particle size in nanoforms ${ }^{3}$. The growing concerns with regard to the potential contribution of phosphorus in poultry excreta on eutrophication of surface waters has led to increasing pressure being placed to limit the amount of excess phosphorus in poultry ration and thus reduce fecal output of phosphorus ${ }^{4}$. Previous work by the same authors

${ }^{*}$ Author for correspondence 
based on production performance in broiler birds have indicated that $50 \%$ of the phosphorus concentration of dicalcium phosphate can be reduced by supplementing calcium phosphate as nanoparticles. However, bioavailability of phosphorus in terms of deposition in target tissue Viz. Bone and the impact on serum mineral profile and carcass characteristics by reducing phosphorus concentration in diet to the extent of 50 per cent through nano particles was not investigated. Hence this study was focused to determine bioavailability of phosphorus in calcium phosphate nanoparticles through bone morphometric, mineral profile and carcass characteristics of broiler chicks.

\section{Materials and Methods}

Seventy day old male broiler chicks (Cobb- 400) belonging to a single hatch were purchased from a commercial farm were wing banded, weighed individually and distributed randomly to the seven experimental groups of 10 chicks each. The experimental birds were housed individually in five tiered, well ventilated battery cages provided with artificial lighting. The management practices adopted were as per the standards and were uniform for all the treatment groups. Graded levels of calcium phosphate nanoparticles (Synthesised following wet chemical $\operatorname{method}^{5}$ ) were included for 28 days. Dicalcium phosphate and calcite were used in control diet. The phosphorus content in dicalcium phosphate was replaced at graded level by calcium phosphate nanoparticles at 50 to 100 per cent at 10 per cent interval. The treatment of $50 \%$ calcium phosphate nanoparticles means a $50 \%$ less than the phosphorous contribution as dicalcium phosphate $(\mathrm{w} / \mathrm{w})$ supplemented in control treatment. A $60,70,80$, 90 and $100 \%$ calcium phosphate nanoparticle mean a 40 , $30,20,10$ and $0 \%$ less phosphorous contribution as dicalcium phosphate supplemented in control respectively. At the end of $28^{\text {th }}$ day, five birds from each treatment were slaughtered. The left tibial bone was dissected out and their adhered muscles together with connective tissue were thoroughly removed manually and boiled in water for five minutes and dried in hot air oven for overnight to study bone characteristics such as physical morphometry and bone ash content. De-fatting of dried bones was carried out using diethyl ether, followed by petroleum spirit, for 16 hours each 6 .

The weight of each tibial bone was recorded and expressed in percentage in proportion to live body weight. Bone morphological parameters were studied as per $^{7}$. The full length of each bone was measured from its proximal to distal end.

The long axis width of each bone was measured at almost one $\mathrm{cm}$ below the proximal end of the dorsal surface (across the flat). The short axis width of each bone was measured at almost one $\mathrm{cm}$ below the proximal end of the lateral surface. The mean value of long axis and short axis width was the actual width of the bone.

Estimation of bone ash (per cent tibia ash) of the dried and defatted bone was carried out as per the method of ${ }^{6}$.

Bone ash was digested in $15 \mathrm{ml}$ of $1+3 \mathrm{HCl}$, distilled water and 10 drops of concentrated nitric acid. The dissolved ash (soluble ash) was filtered via Whatman no 42 filter paper and the soluble ash were made up to 50 $\mathrm{ml}$ using distilled water. The soluble ash was assayed for calcium, magnesium, zinc, copper, iron and manganese content using atomic absorption spectrophotometer (Perkin-Elmer, Model 3110, 1994). Phosphorus content of the soluble ash was determined by Ammonium MolybdoVanadate method prescribed by ${ }^{6}$. The major minerals (calcium, phosphorus and magnesium) content of the bone were expressed in \% per gram of tibia and minor minerals (zinc, copper, iron and manganese) as ppm per gram of tibia.

The carcass parameters like carcass weight, heart weight, liver weight and gizzard weight were recorded and dressing percentage calculated. Heart, liver and gizzard weights were expressed in terms of their per cent body weight.

Serum samples were collected from the birds at $28^{\text {th }}$ day of age and the major minerals calcium, phosphorus, magnesium and minor minerals copper, zinc and manganese were estimated using Atomic Absorption Spectrophotometer (Perkin-Elmer, Model 3110, 1994) as per the procedure outlined in the reference manual. Phosphorus content of the samples was estimated by colorimetric method ${ }^{8}$.

Data were analysed with ANalysis Of VAriance (ANOVA) as per the procedure of statistical analysis system (SPSS, version 17.0 for windows) ${ }^{9}$. When significant difference $(\mathrm{P}<0.05)$ were detected, the multiple range test was used to separate the mean value.

\section{Result and Discussion}

The data on mean tibial weight $(\mathrm{g})$, tibial length $(\mathrm{mm})$ and tibial width $(\mathrm{mm})$, tibial ash and tibial mineral con- 
tent as influenced by various levels of calcium phosphate nanoparticles is presented in Table 1 . There was no significant $(\mathrm{p}<0.05)$ difference in tibial weight, tibial length and width of tibia among the various treatments. The mean tibial weight in broilers in the control group was comparable to the data recorded by ${ }^{10}$. The mean tibial length and tibial width in broilers in the control group were comparable to the data recorded by ${ }^{11}$.

The mean total ash per cent in broilers in the control group were comparable to the data recorded by ${ }^{10}$. Supplementation of calcium phosphate nanoparticles at varying levels did not affect the tibial bone total ash content. The data on mean calcium, phosphorus, magnesium, zinc, copper, iron and manganese content as influenced by various levels of calcium phosphate nanoparticles revealed that there was no significant $(\mathrm{p}<0.05)$ difference among the various treatments in tibial bone mineral contents. The mean calcium and phosphorus in broilers in the control group were comparable to the data recorded by ${ }^{12}$. A non significant difference in weight of the tibia, and mean tibial bone length and width among treatments indicates that the intervention made in feed does not influence the bone. ${ }^{13,14}$ have recorded that calcium phosphate nanoparticles has similar chemical structure to bone and hence has a biocompatibility and bioactivity.

The data on mean carcass weight, heart weight, liver weight, gizzard weight (\% of body weight) and dressing percent as influenced by various levels of calcium phosphate nanoparticles is presented in Table 2 .

Significant difference $(\mathrm{p}<0.05)$ in carcass weight between birds fed with control and 50\% (T1) calcium phosphate nanoparticles was observed. The $50 \%$ calcium phosphate nanoparticles supplementation significantly $(\mathrm{p}<0.05)$ increased carcass weight compared to control. However, when these values were translated to percentage of body weight, a non significant difference was observed in dressing percentage. There was no significant difference observed among the treatments on weight of the heart and liver as such or when converted to percentage of body weight.

There was significant difference $(\mathrm{p}<0.05)$ in gizzard weight between control and treatments except birds fed with $100 \%$ (T6) calcium phosphate nanoparticles. An incremental decrease in gizzard weight was observed as the level of inclusion of calcium phosphate nanoparticles increases. However, when these values were converted to percentage of body weight, an incremental increase in gizzard weight was observed with corresponding increase in supplementation of calcium phosphate nanoparticles that was significantly $(\mathrm{p}<0.05)$ higher than control group.

A non significant difference in dressing percentage, weight of the heart and liver among treatments indicates that the intervention made in feed does not influence the metabolism. However, increase in the weight of gizzard as percentage of body weight indicates that differences in the particle sizes provided for chicken can significantly influence the development of their gut ${ }^{15}$. The gizzard is the principal physical food-processing organ of food in avian species ${ }^{16}$. The mass of the gizzard relative to body weight has been reported to increase with increase in dietary particle size ${ }^{17}$. Since the feed intake is increased corresponding to increase in the level of supplementation of calcium phosphate nanoparticle, the stress of physical food processing would have increased the musculature of gizzard leading to increased weight.

The effect of calcium phosphate nanoparticles on serum mineral profile of broilers is presented in Table 3. There was no significant different among the treatments in the major minerals calcium, phosphorus, magnesium and minor minerals copper, zinc and manganese. The results obtained in this study for serum copper, zinc and manganese in the control diet were in agreement with the observation recorded by ${ }^{18}$, for magnesium by ${ }^{19}$ and for calcium and phosphorus by ${ }^{20}$.

Similar to the results of bone mineral profile, the serum mineral profile also did not show any significant difference due to interventions made which again reinforces the recommendation of reducing the level of phosphorus supplementation to $50 \%$ by calcium phosphate nanoparticles as the birds were healthy.

The non significant difference in tibial bone ash, calcium and phosphorus between the control group which received $100 \%$ dicalcium phosphate and $50 \%$ calcium phosphate nanoparticles groups that received only 50\% of phosphorus of dicalcium phosphate indicated that the bioavailability of calcium phosphate nanoparticles is $200 \%$ when compared to dicalcium phosphate.

\section{Conclusion}

The effect of various levels of calcium phosphate nanoparticles on bone physical morphomerty and mineralization (bone ash) in broilers indicated that comparable in weight of the tibia, and mean tibial bone length and width among treatments which in turn indicates that the interventions made in feed does not influence the bone. Since calcium 


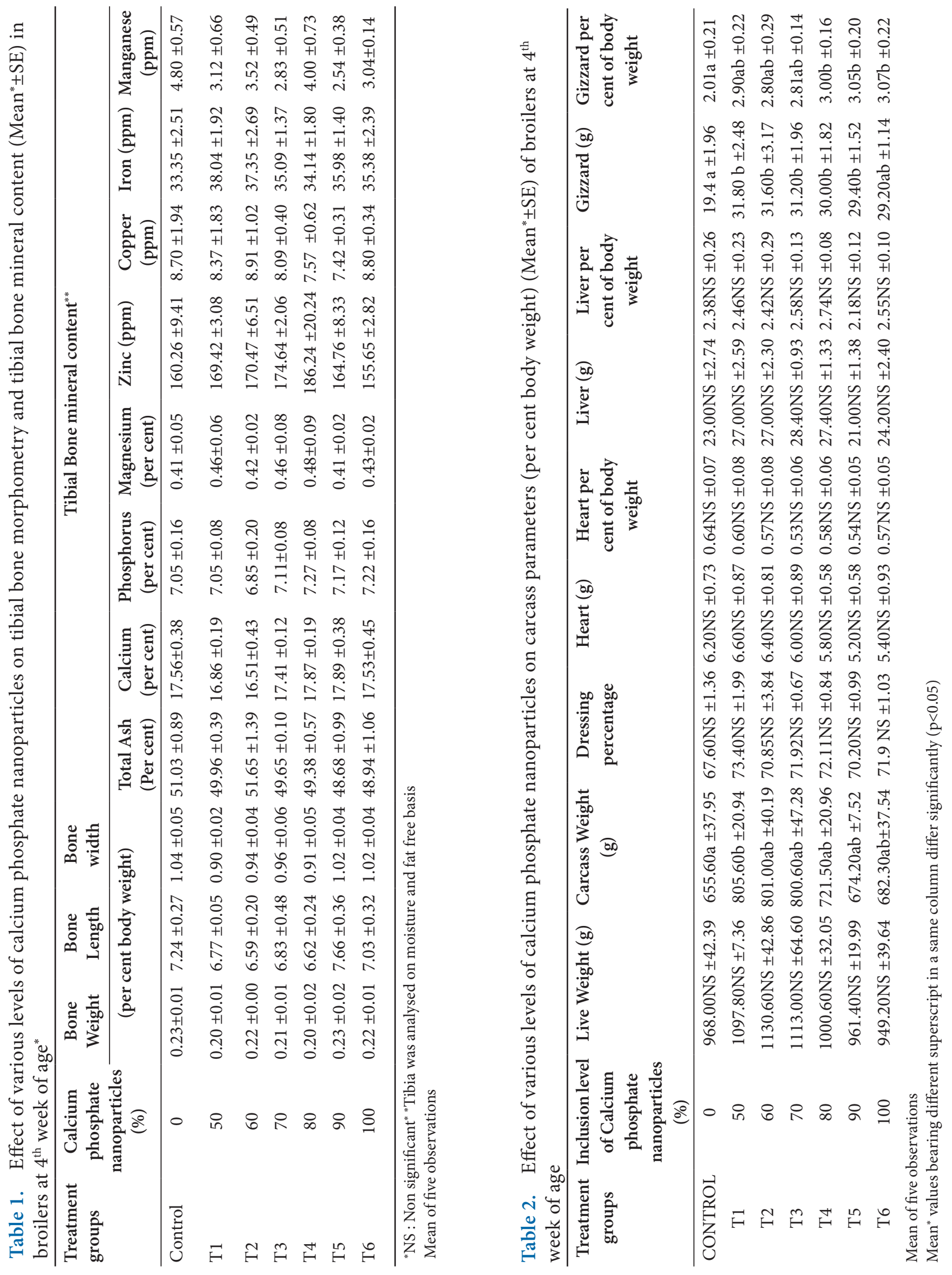


Table 3. Effect of various levels of calcium phosphate nanoparticles on serum mineral profile (Mean* \pm SE) of broilers at $4^{\text {th }}$ week of age*

\begin{tabular}{|c|c|c|c|c|c|c|c|}
\hline \multirow{2}{*}{$\begin{array}{l}\text { Treatment } \\
\text { groups }\end{array}$} & \multirow{2}{*}{$\begin{array}{c}\text { Calcium } \\
\text { phosphate } \\
\text { nanoparticles } \\
(\%)\end{array}$} & \multicolumn{6}{|c|}{ Serum mineral content ${ }^{* *}$} \\
\hline & & $\begin{array}{l}\text { Calcium (mg/ } \\
\text { dl) }\end{array}$ & $\begin{array}{l}\text { Phosphorus } \\
\text { (mg/dl) }\end{array}$ & $\begin{array}{l}\text { Magnesium } \\
(\mathrm{mg} / \mathrm{dl})\end{array}$ & Zinc $(\mu \mathrm{g} / \mathrm{ml})$ & $\begin{array}{c}\text { Copper }(\mu \mathrm{g} / \\
\mathrm{ml})\end{array}$ & $\begin{array}{c}\text { Manganese } \\
(\mu \mathrm{g} / \mathrm{ml})\end{array}$ \\
\hline CONTROL & 0 & $10.56 \mathrm{NS} \pm 0.28$ & $7.15 \mathrm{NS} \pm 0.06$ & $1.51 \mathrm{NS} \pm 0.02$ & $19.26 \mathrm{NS} \pm 0.41$ & $4.70 \mathrm{NS} \pm 0.04$ & $3.80 \mathrm{NS} \pm 0.57$ \\
\hline $\mathrm{T} 1$ & 50 & $10.36 \mathrm{NS} \pm 0.17$ & $7.22 \mathrm{NS} \pm 0.05$ & $1.48 \mathrm{NS} \pm 0.03$ & $19.11 \mathrm{NS} \pm 0.08$ & $4.37 \mathrm{NS} \pm 0.03$ & $3.62 \mathrm{NS} \pm 0.06$ \\
\hline $\mathrm{T} 2$ & 60 & $9.91 \mathrm{NS} \pm 0.33$ & $7.05 \mathrm{NS} \pm 0.10$ & $1.52 \mathrm{NS} \pm 0.02$ & $18.94 \mathrm{NS} \pm 0.51$ & $3.91 \mathrm{NS} \pm 0.02$ & $3.52 \mathrm{NS} \pm 0.09$ \\
\hline T3 & 70 & $9.41 \mathrm{NS} \pm 0.22$ & $7.21 \mathrm{NS} \pm 0.09$ & $1.48 \mathrm{NS} \pm 0.04$ & $19.09 \mathrm{NS} \pm 0.06$ & $4.09 \mathrm{NS} \pm 0.04$ & $3.83 \mathrm{NS} \pm 0.01$ \\
\hline $\mathrm{T} 4$ & 80 & $9.87 \mathrm{NS} \pm 0.29$ & $6.97 \mathrm{NS} \pm 0.11$ & $1.46 \mathrm{NS} \pm 0.05$ & $18.95 \mathrm{NS} \pm 0.24$ & $4.27 \mathrm{NS} \pm 0.02$ & $3.70 \mathrm{NS} \pm 0.03$ \\
\hline T5 & 90 & $9.89 \mathrm{NS} \pm 0.28$ & $6.89 \mathrm{NS} \pm 0.15$ & $1.45 \mathrm{NS} \pm 0.02$ & $19.04 \mathrm{NS} \pm 0.33$ & $4.32 \mathrm{NS} \pm 0.03$ & $3.54 \mathrm{NS} \pm 0.08$ \\
\hline T6 & 100 & $9.53 \mathrm{NS} \pm 0.35$ & $7.29 \mathrm{NS} \pm 0.14$ & $1.47 \mathrm{NS} \pm 0.03$ & $19.06 \mathrm{NS} \pm 0.82$ & $3.80 \mathrm{NS} \pm 0.04$ & $3.44 \mathrm{NS} \pm 0.04$ \\
\hline
\end{tabular}

Mean of five observations

*NS : Non significant; * "Tibia was analysed on moisture and fat free basis

phosphate nanoparticles have similar chemical structure to bone it has better biocompatibility and bioactivity. The tibial bone ash, calcium and phosphorus content are unison for control group (which received $100 \%$ dicalcium phosphate) and 50\% calcium phosphate nanoparticles groups (that received only $50 \%$ of phosphorus of dicalcium phosphate) indicated that the bioavailability of calcium phosphate nanoparticle is $200 \%$ when compared to dicalcium phosphate. The findings may have greater potential in poultry industry especially in feed management and in minimizing the mineral wastages.

\section{References}

1. Weiss J, Takhistov P, McClements J. Functional materials in food Nanotechnology. J Food Sci. 2006; 71(9):107-16.

2. Desai MP, Labhasetwar V, Walter E, Levy RJ, Amidon GL. The mechanism of uptake of biodegradable microparticles in Caco-2 cells is size dependent. Pharm Res. 1997; 14: 1568-73.

3. Gonzales-Eguia A, Fu C-M, Lu F-Y, Lien T-F. Effects of nanocopper on copper availability and nutrients digestibility,growth performance and serum traits of piglets. Livest Sci. 2009; 126:122-9.

4. Waldroup PW. Nutritional Approaches to reducing phosphorus excretion by poultry. Poult Sci. 1999; 78:683-91.

5. Sokolova VV, Radtke I, Heumann R, Epple M. 2006. Effective transfection of cells with multi-shell calcium phosphate-DNA nanoparticles. Biomaterials. 2006; 27:3147-53.

6. AOAC. Official Methods of Analysis. 16th ed. Washington DC: Association of Official Analytical Chemist International; 2000.
7. Shrivastava HP. 1996. Mineral requirements of chickens in tropics. Proc.Sum instt. On Tropical poult. Production. CARI, Izatnagar.

8. AOAC. Official Methods of Analysis. 13th Ed. Washington, DC: Association of Official Analytical Chemist International; 1980.

9. SPSS, Statistical Package for the Social Sciences. version 17.0 software for Windows.

10. Viveros A, Brenes A, Arija I, Centeno C. Effects of microbial phytase supplementation on mineral utilization and serum enzyme activities in broiler chicks fed different levels of phosphorus. Poult Sci. 2002; 81:1172-83.

11. Applegate TJ, Lilburn MS. Growth of the femur and tibia of a commercial broiler line. Poult Sci. 2002; 81:1289-94.

12. Ahmad T, Rasool S, Sarwar M, Haq A-U, Hasan Z-U. Effect of microbial phytase produced from a fungus Aspergillus niger on bioavailability of phosphorus and calcium in broiler chickens. Anim Feed Sci Technol. 2000; 83: 103-14.

13. Gorbunoff MJ. The interaction of proteins with hydroxyapatite : I. Role of protein charge and structure. Anal Biochem. 1984; 136:425-32.

14. Spenlehauer G, Vert M, Benoit JP. In vitro and In vivo degradation of poly(D,L lactide/glycolide) type microspheres made by solvent evaporation method. Biomaterials. 1989; 10:557-63.

15. Nir I, Shefet G, Aaroni Y. Effect of particle size on performance. 1. Corn. Poultry Sci. 1994; 73:45-9.

16. Moore SJ. The functional morphology of an avian herbivore [PhD thesis]. Melbourne: Monah University; 1993.

17. Nir I, Ptichi I. Feed particle size and hardness: Influence on performance, nutritional behavioral and metabolic aspects. Advances in Nutritional Technology, Proceedings of the 
1st World Feed Conference. Utercht, the Netherlands: Wageningen Pers; 2001. p. 157-86.

18. Kumari P, Gupta MK, Ranjan R, Singh KK, Yadava R. Curcuma longa as feed additive in broiler birds and its patho-physiological effects. Indian J Exp Biol. 2007; 45:272-7.
19. Subapriya S, Vairamuthu S, Muralimanohar B, Balachandran C. Clinicopathological Investigation on Thiram toxicosis in broiler chicken. Int J of Poult Sci. 2007; 6(4):242-4.

20. Brenes A, Viveros A, Arija I, Centeno C, Pizarro M, Bravo C. The effect of citric acid and microbial phytase on mineral utilization in broiler chicks. Anim Feed Sci Technol. 2003; 110:201-19. 